\title{
Fluoride supplements useful but increase the risk of mild fluorosis
}

Ismail AT, Bandekar RE. Fluoride supplements and fluorosis: a meta-analysis. Community Dent Oral Epidemiol 1999; 27: $48-56$

Objectives To investigate whether the regular use of fluoride supplements in non-fluoridated communities during the period of tooth development increases the risk of dental fluorosis.

Data sources Medline search 1966-Sept 1997 (English only papers) using following key words: fluorosis, dental, fluoride, fluoride supplement or supplements, drop or drops, and tablet or tablets.

Study selection Twenty-four studies that assessed the development of dental fluorosis in children who had used fluoride supplements were identified. Ten cross-sectional/case control studies and four follow-up studies had data that allowed a quantitative estimation of the risk of developing dental fluorosis in users of fluoride supplements. Ten studies were excluded.
Results A consistent and strong association between the use of fluoride supplements and dental fluorosis was found. Meta-analyses of the cross-sectional/case-control studies estimated the odds ratio of dental fluorosis in users of fluoride supplements between 2.1 and 2.3 (95\% C.I. 1.5-3.4).

Conclusions In non-fluoridated communities, the use of fluoride supplements during the first 6 years of life is associated with a significant increase in the risk of developing a very mild to mild type of dental fluorosis.

Address for reprints: Amid Ismail, Department of Cariology, School of Dentistry, The University of Michigan, 1011 N. University, D2347, Ann Arbor, Michigan, USA.

\section{Commentary}

One of the first reported studies of fluoride tablet administration for the control of dental caries involved children aged 3 years at the start of the study. The dosage regime chosen, $1 \mathrm{mg} / \mathrm{F} /$ day, was an attempt to ensure that the daily intake of fluoride equalled that from the water fluoridated at $1 \mathrm{ppmF}$. This thinking dominated the dosage regimes used for individuals and for communities over the next 35 years. A review by Murray ${ }^{2}$ concluded that there was no doubt that using fluoride tablets or drops was effective in reducing the incidence of dental caries in both deciduous and permanent teeth. They also concluded that the reduction was greater the earlier the child began to take the supplements. Hence, the benefits of fluoride tablet administration are not in question. On the risk side, many studies have shown that the use of fluoride tablets is associated with increased risk of fluorosis. The appropriateness of different dosage schedules has been debated for the last 20 years and a number of bodies such as the American Academy of Paediatrics and the British Association for the Study of Community Dentistry have issued recommendations. One regime for example is $1 / 4 \mathrm{mg} / \mathrm{F} /$ day for children 6 months to 2 years of age, $1 / 2 \mathrm{mg} / \mathrm{F}$ day for children aged 24 years and $1 \mathrm{mg} / \mathrm{F} /$ day for older persons. In Europe a group of researchers and public health workers have proposed just one dosage i.e. $1 / 2 \mathrm{mg} / \mathrm{F} /$ day from the age of 3 years and older. ${ }^{3}$ This recommendation was based on new knowledge on when upper permanent central incisors are most at risk of developing fluorosis ${ }^{4}$ and took account of the difficulties encountered by parents with children of different ages wishing to comply with age-related dosing schedules recommended at the time.

This meta-analysis does not take into account the different dosages used in the studies reviewed which were conducted at different time periods (19741997), during which changes in the recommended dosages of fluoride in tablets were published. The studies reviewed also took place in different countries in which the dosages recommended again varied. These two factors may partly explain the variation in odds ratios found in the different studies. The authors emphasise that most of the fluorosis found in the studies reviewed was of the very mild to mild type. It would seem that use of fluoride supplements still has a useful preventive roll for children with high caries. In these children, the potential risk of developing very mild to mild fluorosis is outweighed by clear benefit of reduced levels of dental decay.

1. Arnold FA, McClure FJ, White, CL. Sodium Fluoride tablets for children. Dental progress 1960; 1:8-12.

2. Murray JJ, Rugg-Gunn AJ, Jenkins GM. Fluorides in Caries Prevention. Chapter 8, 3rd Ed. Butterworth-Heinmann Ltd. Oxford 1991.

3. Clarkson JA. European view of fluoride supplementation. Br Dent J 1992; 172:357.

4. Evans WR, Stamm JW. An epidemiological estimate of the critical period during which human maxillary central incisors are most susceptible to fluorosis. J Pub Hlth Dent 1991; 51:251-257.

Denis O'Mullane

Oral Health Services Research Centre, University of Cork, Ireland 